\title{
Rudbeckia hirta L.: A Versatile North American Wildflower
}

\section{Taxonomic description and history}

The genus Rudbeckia consists of $\approx 25$ annual, biennial, or perennial herbaceous species native to most of North America, except for the extreme northern and southern regions. Most species are concentrated east of the Rocky Mountains (Liberty Hyde Bailey Hortorium, 1976). This genus, a member of the Helianthus tribe within the Asteraceae, was named by Linneaus after father and son Swedish botanists Olaus and Johan Rudbeck (Gledhill, 1989; Kochankov and Chailakhyan, 1986). Rudbeckia species are used widely as ornamentals but have also served as forage, silage, and nectar sources (Kochankov and Chailakhyan, 1986).

The genus Rudbeckia is generally characterized by floral heads composed of disk and ray florets. The ray florets are commonly yellow or orange and sometimes have red markings. The chaffy receptacle can be conical or convex with fertile disk florets and divided styles; it is subtended by more than four involucral bracts. The epidermis is usually rough, and the leaves are alternate, undivided, and lobed or pinnatifid (Wofford, 1989). Rudbeckia are pollinated by insects and, in at least three species, the ultraviolet (UV) reflection patterns are different enough to allow for pollinator discrimination (Abrahamson and McCrea, 1977). The apomictic species, $R$. triloba and $R$. laciniata, have limited intrapopulation variation in UV nectar guide patterns, while $R$. hirta, an obligate outbreeder, has greater variation (Abrahamson and McCrea, 1977). Little evidence of interspecific hybridization exists even though colonies of two or more species may frequently occur in close proximity (Perdue, 1957).

Rudbeckia hirta's in florescence has a prominent central cone of disk florets, normally purplish black, with acute bracts and elongated, subulate styles. The ray florets are bright yellow or yellow with rust markings, giving rise to the common name "black-eyed Susan" or "coneflower." The stems and leaves

Received for publication 3 Sept. 1993. Accepted for publication 2 Nov. 1993. The cost of publishing this paper was defrayed in part by the payment of page charges. Under postal regulations, this paper therefore must be hereby marked advertisement solely to indicate this fact.

${ }^{1}$ Research Associate.

${ }^{2}$ Associate Professor.

Front cover (top row, left to right) An unselected form of R. hirta sharing space with Echinacea purpurea (L.) Moench (purple coneflower); 'Goldilocks'. (center row, left to right) 'Double Gold'; 'Irish Eyes'; 'Autumn Forest'. (bottom row, left to right) Native $R$. hirta in Virginia 'Double Daisy'. (Photographers: R.E. Lyons and R.L. Harkess.) are coarsely hairy, and the species has been considered an annual, biennial, or short-lived perennial depending on location and genetic background. While native to North America, $R$. hirta is one of the most common species of the genus and is frequently observed throughout the world as a result of its successful naturalization abilities.

As cultivated plants, $R$. hirta selections have a nonuniform appearance; bloom from July through August; are not consistently available; and perform well in gardens, wildflower meadow mixes, and as a species component of highway beautification projects. They make excellent cut flowers, but, to our knowledge, their postharvest characteristics have not been researched.

Many forms of $R$. hirta are known, which has led to a plethora of varietal names (Gray Herbarium, 1968). Clute (1913) reported one variation in ray floret coloration as a form of $R$. speciosa, then known as $R$. bicolor. The Gray Herbarium lists $R$. speciosa as a variety of $R$. fulgida, and $R$. bicolor as a variety of $R$. hirta (Gray Herbarium, 1968). In his work with color variation in Rudbeckia, Clute (1913) divided the three main color forms into $R$. hirta var. bicolor, $R$. hirta var. rubra, and $R$. hirta var. annulata, yet he also concluded that these forms were unstable. Later, Clute (1924) reported that the form of $R$. hirta with a red blotch at the base of each ray floret wasR. hirta var. pulcherrima, the same color form he previously listed as $R$. hirta var. bicolor. To further confuse the taxonomic listing of this species, Fernald and Schubert (1948) identified the species $R$. hirta var. pulcherrima as a varietal form of $R$. serotina. This conclusion was based on its strong tendency to sport, whereas $R$. hirta, originating from an older ecological region, was reportedly stable. Perdue (1957) reported $R$. bicolor to be synonymous with $R$. hirta var. pulcherrima as first listed by Farwell ( 1904). The Gray Herbarium later listed $R$. bicolor as a variety of $R$. hirta, separate from $R$. pulcherrima, and reduced $R$. serotina to a variety of $R$. hirta. Most recent classification places $R$. bicolor synonymous with $R$. hirta var. pulcherrima Farw. (Liberty Hyde Bailey Hortorium, 1976) or just $R$. hirta L. (Huxley et al., 1992), yet it is likely that all these plants are marketed for ornamental use simply as $R$. hirta.

As cultivated plants, $R$. hirta selections may be loosely distinguished based on three features: flowering plant height, ray floret color, and single vs. double inflorescences (number of ray florets). 'Becky', a true diminutive standout, is one of the shortest cultivars, growing no taller than 20 to $25 \mathrm{~cm}$. Plant stature appears to be the main breeding objective in developing 'Becky', because its flower size is variable and inflorescence colors range from pure gold to heavily flushed with brown.
Taller cultivars that reliably produce brownor maroon-marked golden flowers include, but are not limited to, 'Autumn Forest', 'Sputnik, 'Nutmeg', 'My Joy', 'Rustic Colors', and 'Rustic Dwarfs'. Unmarked, yellow-gold flowers are generally produced by 'Golden Daisy', 'Goldilocks', 'Marmalade', and 'Pinwheel', all of which exhibit some degree of doubleness. In this group, 'Goldilocks' is the shortest and is similar in size to 'Becky'. 'Double Gold' and 'Double Daisy' are largely what their names imply-monochromatic inflorescences composed of abundant ray florets, resulting in dramatic double flowers. One of the newest cultivars, 'Indian Summer', is a 1995 All-American Selection winner. Each 'Indian Summer' inflorescence reaches 15 to $22 \mathrm{~cm}$ in diameter and has golden-yellow rays and dark disk florets. In our opinion, not all $R$. hirta cultivars are distinctly different, leading to the suspicion that some cultivars may be synonymous, depending on the seed source. 'Irish Eyes', however, is a uniquely beautiful cultivar that possesses a greenish rather than brown cone of disk florets. This trait has been incorporated into a recent bedding plant release of Sanvitalia procumbens Lam., also named 'Irish Eyes' (K. Sahin, Zaden B. V., Rijn, The Netherlands) and a close relative of the genus Rudbeckia. 'Gloriosa Daisy' and 'Double Gloriosa Daisy' are tetraploid strains tending to be more reliably perennial than other cultivars but still blooming the first year from seed as do their diploid counterparts.

\section{Research history}

In the 1920s, Garner and Allard (1925) first described $R$. hirta as a long-day (LD) plant. Since then, it has been used as a model for LD plant photoperiodicity and for flowering research (Austin, 1941; Greulach, 1942; Mumeek, 1936, 1940). These studies focused on the effects of temperature and critical daylength on flowering (Kochankov and Chailakhyan, 1986; Tanimoto and Harada, 1985). Following World War II, European research teams also used $R$. hirta to study flowering. These efforts focused on the physiological effects of plant growth substances, predominantly retardants, on stem growth and flowering (Kochankov and Chailakhyan, 1986; Orvos and Lyons, 1989). Selected effects of applied gibberellins and cytokinins are reported in an article on p. 141 of this HortScience issue (Harkess and Lyons, 1994).

As previously reported by Mumeek (1940) and more recently expanded by Orvos and Lyons (1989), plant height in R. hirta can be controlled by photoperiodic manipulation of its bolting behavior. While in the vegetative stage, the species maintains a flat rosette of leaves. The onset of flower initiation, however, is easily detected by a noticeable arching of the foliar canopy upward and away from the soil surface. The central stem elongates shortly thereafter and may eventually attain a length of $1 \mathrm{~m}$ at the time of terminal inflorescence anthesis, depending on the cultivar. Flowering

(continued on p. 227) 
and stem elongation are not inextricably linked, yet they do respond to the same external LD stimulus. Stem elongation ceases under short days (SD), while floral development, once initiated, does not. In fact, there is no period of total inability to flower in $R$. hirta. Sensitivity to photoperiodic induction increases with age, with the peak sensitivity occurring after the plant has produced $\approx 14$ expanded leaves (Harkess and Lyons, 1993a; Orvos and Lyons, 1989). This vegetative stage signifies maturity in $R$. hirta. In florescence initiation depends on LD; however, once involucral bracts have appeared, a return to SD does not cause development to cease or revert (Harkess and Lyons, 1993 b). As few as eight LDs can initiate flowering in some plants, but usually at least 14 LDs are required for $100 \%$ of the plants to flower. The axillary meristems are affected similarly, but initiate only after terminal meristem initiation (Harkess and Lyons, 1993b). This characteristic cannot be ignored when limited photopenodic treatments are used specifically for height control. Although fewer LD will minimize plant height, the potential number of inflorescences will also be reduced because of a lack of axillary inflorescence production.

Recently, histological examination of the terminal meristem has outlined the major anatomical changes occurring in R. hirta during floral initiation and development (Harkess and Lyons, 1993a). Fluctuations in polyamides have also been correlated to these anatomical changes. Putrescine and spermidine increase during floral initiation and decrease during subsequent development (Harkess et al., 1992). This response is opposite to that observed in SD plants and is similar to results previously reported with cytokinins (Hamasaki and Galston, 1990; Krekule et al., 1989).

Additional research has indicated that, as in other species, ecotype origin has a profound effect on the flowering response of $R$. hirta. An ecotype native to Texas had a weak LD facultative flowering response, while ecotypes native to more northern latitudes were obligate LD plants [Beckwith, 1991). Ecotypes from southern latitudes also flowered earlier and had more leaves on shorter stems than ecotypes from northern latitudes. Such differential flowering responses within $R$. hirta are considered undesirable for production in commercial greenhouses, but they may be worthy of further exploitation for use in meadow seed mixes. The high percentage of mixes that already include this species indicates a proven performance record in this unique landscape use. Yet the potential also exists to extend the overall flowering of $R$. hirta by deliberately combining different ecotypes in the same seed mix. Plant breeders could also capitalize on this feature to produce cultivars better suited to greenhouse production vs. outdoor gardens.

Historically, $R$. hirta has been an important model for flowering research and will continue as such. Recent research confirms this species' photoperiodic response and characterizes some of the changes occurring during floral initiation and development. Unlike plants that respond to a single photoperiodic cycle, $R$. hirta requires several days, which allows a closer examination of individual floral initiation and development stages (Beckwith, 1991; Harkess and Lyons, 1993a, 1993b; Orvos and Lyons, 1989). Despite the considerable variation within $R$. hirta, the plant has reliably and predictably responded to a variety of photoperiodic treatments. In fact, variation can actually be viewed as an asset, whether the species is used for ornamental or basic research purposes.

\section{Literature Cited}

Abrahamson, W.G, and K.D. McCrea. 1977. Ultraviolet light reflection and absorption patterns in populations of Rudbeckia (Composite). Rhodora 79:269-277.

Austin, J.P. 1941, The influence of the length of the 'photoperiod on the vegetative and reproductive development of Rudbeckia bicolor superba, Delphinium ajacis, Cosmos sulphureus, and Impatiens balsamina. Amer. J. Bet. 28:244250.

Beckwith, D.D. 1991. Characterization of juvenility and photoperiodic responses of Rudbeckia hirta originating from different latitudes. MS thesis, Virginia Polytechnic Inst. and State Univ., Blacksburg.

Clute, W.N. 1913. The production of new forms in Rudbeckia. Amer. Bet. 19:131-134

Clute, W.N. 1924. Elementary species of Rudbeckia. Amer. Bet. 30: 158-159.

Farwell, O.A, 1904. Contributions to the botany of Michigan. no. 8. Rpt. Mich. Acad. Sci. 6:200214.

Fernald, M.L. and B.G. Schubert. 1948. Studies of American types in British herbaria. Rhodora 50:149-176.

Gamer, W.W. and H.A. Allard. 1925. Localization of the response in plants to relative length of day and night. J. Agr. Res. 31:555-566.

Gledhill, D. 1989. The names of plants. Cambridge University Press, Cambridge, U.K.
Gray Herbarium. 1968. Gray Herbarium index, Harvard University. vol. 9. G.K. Hall and Co., Boston.

Greulach, V.A. 1942. Photoperiodic after-effects in six composites. Bet. Gaz. 103:698-709.

Hamasaki, N. and A.W. Galston. 1990. The polyamides of Xanthium strumarium and their response to photopenod. Photochem. Photobiol. 52:181-186.

Harkess, R.L. and R.E. Lyons. 1993a. Anatomical changes in Rudbeckia hirta L. during transition to flowering. J. Amer. Soc. Hort. Sci. 118:835839.

Harkess, R.L. and R.E. Lyons. 1993b. Floral initiation in Rudbeckia hirta under limited inductive photopenodic treatments. HortScience 28:572. (Abstr.)

Harkess, R.L. and R.E. Lyons. 1994. Gibberellinand cytokinin-induced growth and flowering responses in Rudbeckia hirta L. HortScience 29:141-142.

Harkess, R. L., R.E. Lyons, and M.M. Kushad. 1992. Floral morphogenesis in Rudbeckia hirta in relation to polyamine concentration. Physiol. Plant. 86:575-582.

Huxley, A., M. Griffiths, and M. Levy. 1992. The New Royal Horticultural Society dictionary of gardening. vol. 4. Stockton Press, New York. p. 145-146.

Kochankov, V. and M.Kh. Chailakhyan. 1986. Rudbeckia, p. 295-320. In: A. Halevy (ed.). CRC handbook of flowering. vol. V. CRC Press, Boca Raton, Fla.

Krekrde, J., I. Machácková, L. Pavlová and F. Seidlová 1989. Hormonal signals in photopenodic control of flower initiation, p. 145-1 62. In: J. Krekule and F. Seidlová (eds.). Signals in plant development. SPB Academic Publishing, The Hague, The Netherlands.

Liberty Hyde Bailey Hortorium. 1976. Hortus third. Macmillan, New York.

Murneek, A.E. 1936. A separation of certain types of response of plants to photoperiod. Proc. Amer. Soc. Hort. Sci. 34:507-509.

Murneek, A.E. 1940. Length of day and temperature effects in Rudbeckia. Bet. Gaz. 102:269-279.

Orvos, A.R. and R.E. Lyons. 1989. Photoperiodic inhibition of stem elongation and flowering in Rudbeckia hirta 'Marmalade'. J. Amer. Soc. Hort. Sci. 114:219-222.

Perdue, R.E. 1957. Synopsis of Rudbeckia subgenus Rudbeckia. Rhodora 59:293-299.

Tanimoto, S. and H. Harada. 1985. Rudbeckia, p. 239-242. In: A. Halevy (ed.). CRC handbook of flowering. vol. IV. CRC Press, Boca Raton, Fla.

Wofford, B.E. 1989. Guide to the vascular plants of the Blue Ridge. Univ. of Georgia Press, Athens.

Richard L. HARKESS ${ }^{1}$ and RoBERT E. LyONS ${ }^{2}$ Dept. of Horticulture Virginia Polytechnic Institute and State Univ.

Blacksburg, VA 24061-0327 